\title{
Comparison of propofol-nalbuphine and propofol-fentanyl sedation for patients undergoing endoscopic retrograde cholangiopancreatography: a double-blind, randomized controlled trial
}

Peiqi Wang ${ }^{1}$, Yan Chen ${ }^{1}$, Ying Guo ${ }^{1}$, Jiangbei Cao ${ }^{1}$, Hong Wang ${ }^{1}$, Weidong $\mathrm{Mi}^{1{ }^{*+}}$ and Longhe $\mathrm{Xu}^{1,2^{*}+}$

\begin{abstract}
Background: Endoscopic retrograde cholangiopancreatography (ERCP) has been increasingly used to treat patients with biliary/pancreatic duct obstruction or stricture outside the operating room. Effective and safe sedation techniques are needed because of painful stimuli and the long duration of the ERCP procedure.Nalbuphine has been shown to cause less respiratory depression during sedation than similar cases without nalbuphine. This study compared the effects of propofol-nalbuphine (PN) and propofol-fentanyl (PF) sedation in patients undergoing ERCP.

Methods: Four hundred patients scheduled for ERCP procedures were divided into two groups: the PF group (receiving PF sedation, $n=199$ ) and the PN group (receiving PN sedation, $n=201$ ). Vital signs, adverse events during surgery, patient movement scores, pain scores, and adverse events one day post-ERCP were recorded.

Results: Stable haemodynamics were observed in both groups.Compared to the PF group, the PN group showed significantly decreased respiratory depression $(P<0.0001)$ and surgical interruptions $(P=0.048)$. Nalbuphine decreased patient movement by reducing pain from ERCP.
\end{abstract}

Conclusion: Nalbuphine, instead of fentanyl, precipitated less respiratory depression while permitting adequate/ equivalent sedation for ERCP and therefore provides more efficient and safer sedation.

Trial registration

ChiCTR, ChiCTR1800016018, Registered 7 May 2018, http://www.chictr.org.cn/showproj.aspx?proj=27085

Keywords: ERCP, Nalbuphine, Fentanyl, Sedation, Adverse effects

*Correspondence: wwdd1962@aliyun.com; wwdd1962@163.com; longhexu301@aliyun.com; 2568891805@qq.com

'Weidong Mi and Longhe Xu contributed equally to this work.

1 Department of Anaesthesiology, The First Medical Center, Chinese PLA General Hospital, Beijing 100853, China

Full list of author information is available at the end of the article

\section{Background}

Endoscopic retrograde cholangiopancreatography(ERCP) is performed by gastroenterologists or surgeons to investigate abnormalities of the common bile duct, pancreatic ducts, and ampulla. It can also be used to perform certain therapeutic interventions [1]. Although the decrease in diagnostic ERCP was largely precipitated by magnetic resonance cholangiopancreatography (MRCP) and endoscopic ultrasound (EUS) [2, 3],ERCP has been original author(s) and the source, provide a link to the Creative Commons licence, and indicate if changes were made. The images or other third party material in this article are included in the article's Creative Commons licence, unless indicated otherwise in a credit line to the material. If material is not included in the article's Creative Commons licence and your intended use is not permitted by statutory regulation or exceeds the permitted use, you will need to obtain permission directly from the copyright holder. To view a copy of this licence, visit http://creativecommons.org/licenses/by/4.0/. The Creative Commons Public Domain Dedication waiver (http://creativeco mmons.org/publicdomain/zero/1.0/) applies to the data made available in this article, unless otherwise stated in a credit line to the data. 
increasingly used to treat biliary/pancreatic duct blockage or narrowing by stones,tumours,or inflammation outside the operating room $[4,5,6]$. The procedure lasts from 30 to $60 \mathrm{~min}$, and the patients need to be in the prone or semiprone position [7]. Patients usually cannot tolerate the procedure because of pain, the uncomfortable position,fear and nausea without adequate sedation [8].Therefore, ERCP is generally performed under moderate to deep sedation with adequate analgesia to ensure the success of the procedure and improve patient comfort [9].If used as the only anaesthetic agent,an increased dose of propofol may cause undesirable side effects while lacking adequate analgesic effects to inhibit visceral traction pain [10]. Compared to the administration of propofol alone,the application of propofol with fentanyl for ERCP can reduce the total dose of propofol, decrease the pain level, increase practitioner satisfaction, and provide haemodynamic stability but is more likely to induce respiratory depression, muscle stiffness and airway obstruction $[11,12]$.

Hypoxia is a common occurrence during upper GI endoscopy under sedation [13, 14], and prolonged hypoxia is the most common cause of cardiac arrhythmia and coronary ischaemia [13]. Avoiding respiratory depression is helpful to reducethe incidence of hypoxia and has been recommended by the American Society of Anesthesiologists and the American Society for Gastrointestinal Endoscopy [15].Nalbuphine is a mixed agonist-antagonist opioid with a duration of action of approximately $3-6 \mathrm{~h}$ and causes less respiratory depression than fentanyl $[16,17]$. It has also been used to treat pain over the past 40 years [18]. Considering the unique pharmacology in pain management [19], nalbuphine is possibly superior to fentanyl in ERCP due to the lower respiratory depression and adequate analgesia provided by nalbuphine.

In this prospective, double-blind, randomized controlled trial, we compared the analgesic efficacy and safety of propofol combined with nalbuphine or fentanyl in patients undergoing ERCP.We hypothesized that patients sedated with nalbuphine and propofol would have a lower rate of hypoxia during ERCP procedures than patients sedated with fentanyl and propofol.

\section{Methods}

\section{Study design}

This prospective, double-blind, randomized controlled clinical trial was approved by the ethics committee of Chinese PLA General Hospital (S2017-075-02) and was registered in the Chinese Clinical Trial Registry (ChiCTR1800016018,07/05/2018)before its initiation in May 2018. Written informed consent was obtained from all patients.All investigators, including nurses and anaesthetists, received standardized training.

\section{Patient recruitment and exclusion}

The patients included in this study were those who were scheduled for elective ERCP, aged 18 to 79 years, had a BMI of $18.5 \sim 30 \mathrm{~kg} \cdot \mathrm{m}^{-2}$ and were classified as ASA I-III. The exclusion criteria were as follows: (i) clear diagnosis of heart disease (heart failure,angina, myocardial infarction, arrhythmia, etc.); (ii) clear diagnosis of pulmonary disease (asthma, chronic obstructive pulmonary disease, pulmonary embolism, pulmonary oedema, or lung cancer); (iii) central nervous system abnormality; (iv) allergy to the study drugs; (v)pregnancy; and (vi)anticipated difficult airway.

\section{Grouping design and study procedure}

The patients were randomly divided into 2 groups, the PN group(propofol and nalbuphine) and the PF group (propofol and fentanyl),by using a computer-generated randomization table. All of the patients were admitted to the hospital at least 1 day before ERCP.

The procedure was performed in the endoscopy suite by 1 of the 3 gastroenterologists in the institution, who had the experience of performing at least 500 ERCP procedures each. An experienced anaesthesiologist administered the drugs, and an anaesthesia resident collected the clinical data. We prefilled $5-\mathrm{ml}$ syringes with either $4 \mathrm{ml}$ of liquid fentanyl $\left(50 \mu \mathrm{g} \mathrm{m}^{-1}\right)$ or $4 \mathrm{ml}$ nalbuphine $\left(5 \mathrm{mg} \mathrm{ml}^{-1}\right)$ and labelled them with randomized numbers. In this way, all patients, the anaesthesiologist, the anaesthesia resident and the gastroenterologists were blinded to the group information.

All patients were placed in prone position. They all received midazolam and propofol for sedation and were then monitored for sedation depth using the bispectral index (BIS). Midazolam (0.01-0.02 $\mathrm{mg} \mathrm{kg}^{-1}$ ) was initially administered. Patients in the PN group received 0.1-0.2 $\mathrm{mgkg}^{-1}$ nalbuphine and $1-2 \mathrm{mgkg}^{-1}$ propofol intravenous injection over 30s followed by an infusion of propofol at 0.05 to $0.1 \mathrm{mg}\left(\mathrm{kg} \mathrm{min}^{-1}\right.$, and patients in the PF group received $1-2 \mathrm{\mu gkg}^{-1}$ fentanyl and $1-2 \mathrm{mgkg}^{-1}$ propofol injection over 30s followed by an infusion of propofol at 0.05 to $0.1 \mathrm{mg}\left(\mathrm{kg} \mathrm{min}^{-1}\right.$.The BIS index was used to assess the level of sedation, and a value of 40-60 was targeted for the procedure [20]. In cases of an index $>60$ or sudden patient movement, propofol $20-30 \mathrm{mg}+$ nalbuphine $5 \mathrm{mg}$ or propofol $20-30 \mathrm{mg}+$ fentanyl $50 \mu \mathrm{g}$ were given in an intravenous bolus to the assigned groups as rescue drugs. The procedure was allowed to start at the discretion of the attending anaesthesiologist.

Baseline vital signs were recorded immediately before the procedure. Oxygen was delivered by nasalprongs at 
4Lmin ${ }^{-1}$ or by an endoscopic facial mask at $4 \mathrm{Lmin}^{-1}$, and a balanced salt solution at $4 \mathrm{~mL}(\mathrm{kghr})^{-1}$ was givenduring the procedure. All patients received BIS (BIS VISTA $^{\mathrm{TM}}$ monitoring system, Aspect Medical Systems Inc., Norwood, MA, USA) at 1-min intervals for the first $3 \mathrm{~min}$ after induction and every $3 \mathrm{~min}$ thereafter. Heart rate (HR), noninvasive mean blood pressure (NBP), respiratory rate (RR), and oxygen saturation $\left(\mathrm{SpO}_{2}\right)$ were documented every $5 \mathrm{~min}$. The situation regarding surgical interruptions was recorded. A modified Aldrete score of 9 was considered recovery, and the patient was transported back to the ward after meeting discharge criteria. The score of patient movement was marked during the operation as follows: no movement (10 points); slight movement, occasionally( 8 points); slight movement, frequently(6 points);severe movement only with the arms and legs (4 points); severe movement with the body and head ( 2 points).The endoscopist and attending anaesthesiologist assessed the process of the procedure at the end and rated it as (I) satisfactory,(II) indeterminate, and(III) not satisfactory. All of the patients were interviewed by the patient sedation satisfaction assessment tool (PSSI) regarding their experience 1 day after the operation.Adverse effects such as nausea, vomiting, pruritus, polypnea and dyspnoea, pain score(visual analogue score,VAS),etc. were noted.The total dose of the study drug and propofol in each group were calculated.

Hypoxia-related adverse events were described as follows: subclinical respiratory depression $(90 \leq \mathrm{SPO} 2<95 \%$ for $>10 \mathrm{~s}$ ) and hypoxia $(\mathrm{SpO} 2<90 \%$ for $>10 \mathrm{~s})$. There were two degrees of hypoxia: mild risk $(75 \leq \mathrm{SPO} 2<89 \%)$ and severe risk $(\mathrm{SPO} 2<75 \%)$. It was corrected using the following protocols: (I) opening the airway with the jaw-thrust manoeuvre; (II) placing the nasopharyngeal airway; (III) turning over to the supine position; and (IV) tracheal intubation for mechanical ventilation.The endoscope was removed if hypoxemia could not be corrected. The attending anaesthesiologist provided immediate airway support, and the procedure was resumed or abandoned at the discretion of the anaesthesiologist. Hypotension and bradycardia were treated with intravenous ephedrine $0.1 \mathrm{mgkg}^{-1}$ and atropine 10 ${\mu \mathrm{gkg}^{-1}}$,respectively.

\section{Randomization and sample size estimations}

A computer-generated randomizationtable was used for the study centre. The randomization sequence was generated by a research assistant who was independent of the study and did not have contact with the study participants.Randomization was performed using opaque sealed envelopes before the induction of anaesthesia.
In this study, the sample size was estimated based on the incidence of hypoxia $\left(\mathrm{SPO}_{2}<90 \%\right.$ for $\left.>10 \mathrm{~s}\right)$ as the main evaluation index. According to the literature, the incidence of $\mathrm{SPO}_{2}$ less than $90 \%$ and over $10 \mathrm{~s}$ is $42.8 \%$ in ERCP when using fentanyl and propofol for sedation $[10,11]$. It was assumed that the incidence of hypoxemia in the PN group was comparable to that in the PF group. Assuming an $\alpha$ value of 0.025 , an a $\beta$ value of 0.2 and a $\delta$ value of 0.15 , we needed a sample size of 171 for each group according to PASS 11 (NCSS, LLC., Kaysville, UT, USA) software. Allowing for a dropout rate of $10 \%$, we calculated that a minimum of 380 cases would need to be enrolled. Considering potential loss to follow-up, we increased the sample size of each group to 200 patients.

\section{Statistical analysis}

The data are shown as the mean \pm SD or percentage as appropriate. Thet test was used to compare the two groups, and if the data distribution was skewed, the Wilcoxon test was used.The $x^{2}$ test and Fisher's exact test were used to compare the incidence of adverse events between the two groups. A p value $<0.05$ was considered statistically significant.All statistical analyses were performed using SPSS version 16(SPSS Inc., Chicago, IL, USA).

\section{Results}

This study recruited 400 patients scheduled for ERCP from May 2018 to June 2019 at our centre.The patients were randomized to two groups.The PN group included 201 patients, and the PF group had 199 patients. The

Table 1 Patient characteristics and procedure details

\begin{tabular}{lll}
\hline & GroupPF( $\boldsymbol{n}=\mathbf{1 9 9})$ & GroupPN( $=\mathbf{2 0 1})$ \\
\hline Age(yr) & $58.09 \pm 13.51$ & $57.91 \pm 13.42$ \\
Age range(yr) & $21-79$ & $24-79$ \\
Age & $132 / 67$ & $133 / 68$ \\
grouping(n,18-64/65-79 yr) & & \\
Gender(male/female) & $132 / 67$ & $124 / 77$ \\
BMl(kgm $\left.{ }^{-2}\right)$ & $22.68 \pm 3.63$ & $22.86 \pm 3.15$ \\
Mallampati Class(n,l/I/III) & $14 / 183 / 2$ & $13 / 185 / 3$ \\
ASA grading(n,I/I/III) & $22 / 131 / 46$ & $19 / 132 / 50$ \\
Duration of anaesthesia(min) & $44.91 \pm 28.77$ & $43.73 \pm 24.76$ \\
Duration of operation(min) & $37.43 \pm 27.96$ & $36.62 \pm 24.15$ \\
ERCP indication(n,\%) & & \\
Choledocholithiasis & $105(52.76 \%)$ & $93(46.28 \%)$ \\
Gall bladder carcinoma & $16(8.04 \%)$ & $15(7.47 \%)$ \\
Biliary strictures & $16(8.04 \%)$ & $22(10.95 \%)$ \\
Pancreatic pathology & $24(12.06 \%)$ & $33(16.39 \%)$ \\
Pancreatic carcinoma & $20(10.05 \%)$ & $23(11.44 \%)$ \\
Others & $18(9.05 \%)$ & $15(7.47 \%)$ \\
\hline
\end{tabular}


patients' characteristics(age, sex, BMI, ASA classification, and Mallampati scores)and procedure details(surgical time and types of the procedure)are compared in Table 1 $(p>0.05)$. Most of the procedures were performed within one hour.Choledocholithiasis was the most common indication for ERCP.

There were no significant differences in the haemodynamic features of the patients (HR, MAP, RR, and SpO2) between the two groups $(p>0.05)$,although the PF group showed greater fluctuation than the PN group did in HR, $\mathrm{MAP}$ and $\mathrm{SpO} 2$.

Respiratory depression was the primary outcome, and surgical interruptions were the secondary outcome in the study.Adverse events such as respiratory depression and interruptions during the procedure are listed in Table 2. The PN group had a significant decrease in the total percentage of respiratory depression compared with that in the PF group ( $p<0.0001,95 \%$ CI:1.04-3.93). Fourteen $(14 / 199,7.04 \%, p=0.03,95 \%$ CI: $0.86-1.88)$ patients had hypoxia, and 5 (5/199,2.51\%, $p=0.048,95 \%$ CI: $1.17-2.45)$ patients developed severe hypoxia in the PF group, while there were only $6(6 / 201,2.99 \%)$ patients with hypoxia and $1(1 / 201,0.50 \%)$ patient with severe hypoxia in the PN group.Respiratory depression was not associated with age, as patients aged 18-64 yr $(p<0.0001,95 \%$ CI: $1.04-$ $1.94)$ and $65-79$ yr $(p<0.0001,95 \%$ CI: $0.87-2.07)$ had more respiratory depression in the PF group than in the PN group.

In the PN group, 12(12/201, 5.97\%) patients received a combined method of correcting respiratory depression, which was significantly lower $(p<0.0001,95 \% \mathrm{CI}$ : $1.04-3.93)$ than that in the PF group (24/199, 12.06\%).
There were 8 patients who needed assisted ventilation with jaw thrusts in the PN group and 12 such patients in the PFgroup.One patient in the PN group require da jaw thrust and a nasopharyngeal airway versus 4 patients in the PF group. There were 3 patients in the PN group and 6 patients in the PF group who were turned to the supine position and received assisted ventilation with two methods.Two patients needed tracheal intubation for mechanical ventilation in the PF group, while no patient had tracheal intubation in the PN group.There were no differences in the rescue methods between the two groups.

In the PFgroup, $45(45 / 199,22.61 \%)$ cases were interrupted during the procedure by patient movement or desaturation ( 2 patients underwent tracheal intubation), while $30,30 / 201,14.93 \%)$ cases were interrupted in the PN group ( $p=0.02,95 \%$ CI: $1.02-1.57)$. There were no differences in the score of patient movement between the two groups.

Table 3 Total dose of drugs given during ERCP

\begin{tabular}{|c|c|c|}
\hline Total dose of drugs & GroupPF $(n=199)$ & GroupPN $(n=201)$ \\
\hline Midazolam(mg) ${ }^{\text {b }}$ & $1.09 \pm 0.26$ & $1.09 \pm 0.25$ \\
\hline Propofol $(m g)^{b}$ & $229.4 \pm 139.0$ & $234.6 \pm 118.2$ \\
\hline Study drug $(\mathrm{ml})^{\mathrm{b}}$ & $2.21 \pm 0.62$ & $2.14 \pm 0.53$ \\
\hline Intravenous ephedrine(n,\%) ${ }^{a}$ & $7(3.52 \%)$ & $7(3.48 \%)$ \\
\hline Atropine $(n, \%)^{a}$ & $15(7.54 \%)$ & $20(9.95 \%)$ \\
\hline
\end{tabular}

Values are presented as the frequency (\%),Chi-squared test ${ }^{\mathrm{a}}$.Values are presented as the mean $\pm S D$, one-sample $t$ test ${ }^{\mathrm{b}}$.Study drug: fentanyl $(50 \mu \mathrm{g} / \mathrm{ml})$ or nalbuphine $(5 \mathrm{mg} / \mathrm{ml})$

Table 2 Adverse events and interruptions during the procedure

\begin{tabular}{|c|c|c|c|c|c|}
\hline & GroupPF $(N=199)$ & GroupPN $(N=201)$ & $p$ value & $95 \% \mathrm{Cl}$ & Odds ratio \\
\hline Respiratory depression(n)\% ${ }^{a}$ & $24(12.06 \%)$ & $12(5.97 \%)$ & $<0.0001$ & $1.04-3.93$ & 2.16 \\
\hline subclinical respiratory ${ }^{a}$ depression $(n) \%^{a}$ & $10(5.03 \%)$ & $6(2.99 \%)$ & 0.14 & $0.86-1.88$ & 1.72 \\
\hline hypoxia(n)\% ${ }^{a}$ & $14(7.04 \%)$ & $6(2.99 \%)$ & 0.03 & $1.06-1.95$ & 2.46 \\
\hline minor risk hypoxia(n)\% ${ }^{a}$ & $9(4.52 \%)$ & $5(2.49 \%)$ & 0.13 & $0.87-1.96$ & 1.86 \\
\hline severe risk hypoxia(n)\% ${ }^{a}$ & $5(2.51 \%)$ & $1(0.50 \%)$ & 0.048 & $1.17-2.45$ & 1.69 \\
\hline 18-65y Age-related Respiratory depression(n)\% ${ }^{a}$ & $15(11.36 \%)$ & $7(5.26 \%)$ & $<0.0001$ & $1.04-1.94$ & 2.31 \\
\hline 66-80y Age-related Respiratory depression(n)\% ${ }^{a}$ & $9(13.43 \%)$ & $5(7.35 \%)$ & $<0.0001$ & $0.87-2.07$ & 1.96 \\
\hline Correction of hypoxia(n)\% ${ }^{a}$ & $24(12.06 \%)$ & $12(5.97 \%)$ & $<0.0001$ & $1.04-3.93$ & 2.16 \\
\hline Method I(n)\% ${ }^{a}$ & $12(6.03 \%)$ & $8(3.98 \%)$ & 0.24 & $0.84-1.77$ & 1.55 \\
\hline Methods I+II(n)\% ${ }^{a}$ & $4(2.01 \%)$ & $1(0.50 \%)$ & 0.09 & $1.03-2.54$ & 1.62 \\
\hline Methods I+ II+III(n)\% ${ }^{a}$ & $6(3.02 \%)$ & $3(1.49 \%)$ & 0.15 & $0.84-2.17$ & 2.05 \\
\hline Methods $I+I I+I I+I V(n) \%^{a}$ & $2(1.01 \%)$ & $0(0.00 \%)$ & 0.07 & $1.83-2.23$ & 2.02 \\
\hline Surgical interruptions $(n) \%^{a}$ & 45 (22.61\%) & $30(14.93 \%)$ & 0.02 & $1.02-1.57$ & 1.27 \\
\hline The score for patient movement(points) ${ }^{b}$ & $9.61 \pm 1.01$ & $9.59 \pm 1.07$ & 0.37 & $-0.23-0.25$ & --- \\
\hline
\end{tabular}

Values are presented as the frequency (\%),Chi-squared test ${ }^{\mathrm{a}}$.Values are presented as the mean $\pm S D$, one-sample $t$ test ${ }^{b}$. Methods: (I) opening the airway with the jawthrust manoeuvre; (II) placing the nasopharyngeal airway; (III) turningthe patients over to the supine position; and (IV) tracheal intubation for mechanical ventilation 
Table 4 Satisfaction score and hospitalization days

\begin{tabular}{|c|c|c|}
\hline & GroupPF $(n=199)$ & GroupPN $(n=201)$ \\
\hline Endoscopist score $(n, 1 / / 1 / / I I)^{a}$ & $188 / 8 / 3$ & 189/11/1 \\
\hline $\begin{array}{l}\text { Anaesthesiologistscore }(\mathrm{n}, \mathrm{l} \\
\mathrm{II/III}^{\mathrm{a}}\end{array}$ & $178 / 19 / 2$ & $185 / 15 / 1$ \\
\hline PSSI score(points) ${ }^{b}$ & $21.10 \pm 3.82$ & $21.01 \pm 4.08$ \\
\hline 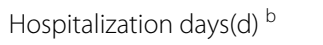 & $7.93 \pm 9.80$ & $7.42 \pm 7.02$ \\
\hline
\end{tabular}

Values are presented as the frequency (\%),Chi-squared test ${ }^{\mathrm{a}}$.Values are presented as the mean \pm SD,One-sample $t$ test ${ }^{\mathrm{b}}$.Score:(I)satisfactory;(II) indeterminate;(III)not satisfactory. PSSI: patient sedation satisfactionassessment tool. Hospitalization days: time for discharge after surgery

The total doses of drugs, including midazolam,propofol, fentanyl, nalbuphine, ephedrine, and atropine, are shown in Table 3(p>0.05).

The endoscopists rated more cases as (III) not satisfactoryin the PF group (Table 4). Eight patients in the PF group and 11 in the PN group were rated as (II) indeterminate. Additionally, anaesthesiologists rated fewer cases as (III) not satisfactory and (II) indeterminate in the PN group. There were no differences in the satisfaction scores of either endoscopistsor anaesthesiologists between the two $\operatorname{groups}(p>0.05)$. The satisfaction scores of the patients were similar in both groups $(p>0.05)$. They were discharged approximately seven days after surgery, and no significant differences were observed in hospitalization days between the two groups $(p>0.05)$.

The incidence of postoperative adverse effects one day after ERCP in the two groups is shown in Table5. Some patients had nausea, vomiting and abnormal pain in both groups $(p>0.05)$.A small number of patients had fever, and only one patient had polypnea and dyspnoeaon Day 1 after the operation in both groups $(p>0.05)$.The symptoms of 2 patients were improved by nasal oxygen supplementation. None of the patients reported any experience of pruritus, aspiration pneumoniaor cough.

\section{Discussion}

Our findings show that propofol-nalbuphine sedation for ERCP significantly decreased the incidence of respiratory depression and surgical interruption compared to that with propofol-fentanyl sedation. Moreover, we observed no differences in the analgesic efficacy and haemodynamic features between the two groups.

ERCP is a complex process that requires deep sedation to be completed successfully [21, 22]. However, adverse events, especially respiratory depression, often occur in prone positions during deep sedation [23, 24].Candan Hayturalet al.showed that propofol combined with opioids provides more effective and reliable sedation for ERCP;however, it can still cause respiratory depression and even hypoxia $[10,11,12]$.These results are consistent with ours, in which the incidence of respiratory depression was $12.06 \%$ in the PF group, and 14 patients developed hypoxia. Even worse, 5 patients developed severe hypoxia, among whom 2 patients had endotracheal intubation. Therefore, the operation had to be interrupted to correct hypoxia. This event may have reduced the satisfaction of the anaesthesiologist and endoscopist, although the patients were unaware of what had happened.However, such conditions were significantly improved in the PN group, and none of the patients underwent endotracheal intubation. Sedation in the PN group greatly lowered the risks of airway management and enhanced the patient safety during the procedure.

The low incidence of respiratory depression in the PN group may be related to the pharmacological properties of nalbuphine [25].Nalbuphine hydrochloride produces

Table 5 Adverse eventsone day after ERCP

\begin{tabular}{|c|c|c|c|c|c|}
\hline & GroupPF $(N=199)$ & GroupPN $(N=201)$ & $P$ value & $95 \% \mathrm{Cl}$ & Odds ratio \\
\hline Total adverse events(n)\% ${ }^{a}$ & $49(23.62 \%)$ & $52(25.88 \%)$ & 0.38 & $0.77-1.22$ & 0.94 \\
\hline Nausea(n)\% ${ }^{a}$ & $20(10.05 \%)$ & $18(8.96 \%)$ & 0.35 & $0.78-1.47$ & 1.14 \\
\hline Vomiting(n)\% a & $11(5.53 \%)$ & $11(5.47 \%)$ & 0.49 & $0.65-1.55$ & 1.01 \\
\hline Pruritus(n)\% & 0 & 0 & NS & & \\
\hline Aspiration pneumonia(n)\% & 0 & 0 & NS & & \\
\hline Cough(n)\% & 0 & 0 & NS & & \\
\hline Polypnea and dyspnoea(n)\% ${ }^{a}$ & $1(0.50 \%)$ & $1(0.50 \%)$ & 0.50 & $0.25-4.03$ & 1.01 \\
\hline Abdominal pain(n)\% ${ }^{a}$ & $15(7.54 \%)$ & $16(7.96 \%)$ & 0.44 & $0.67-1.42$ & 0.94 \\
\hline VAS score(points) ${ }^{b}$ & $0.16 \pm 0.75$ & $0.13 \pm 0.62$ & 0.11 & $-0.03-0.15$ & --- \\
\hline Fever(n)\% ${ }^{a}$ & $2(1.01 \%)$ & $6(2.99 \%)$ & 0.08 & $0.15-1.66$ & 0.33 \\
\hline Medical treatment for adverse events(n)\% ${ }^{a}$ & $17(8.54 \%)$ & $18(8.96 \%)$ & 0.44 & $0.8-1.39$ & 0.95 \\
\hline
\end{tabular}

Values are presented as the frequency (\%),Chi-squared test ${ }^{\mathrm{a}}$.Values are presented as the mean \pm SD. One-sample t test ${ }^{\mathrm{b}}$.VAS score visual analogue score, NA not available 
less respiratory inhibition than opioids at the same analgesic dose.It also has a ceiling effect so that respiratory depression does not increase with the dose when it is greater than $30 \mathrm{mg}[25,26,27,28]$. B. Lefevreet al suggested that nalbuphine should be considered a suitable alternative to fentanyl for use in patients undergoing oral surgery because of less respiratory depression [17]. Furthermore, Chaoyi Deng et al. showed that nalbuphine may be a reasonable alternative to sufentanil in patients undergoing colonoscopy29.In addition,while nalbuphine can effectively antagonize opioid-induced respiratory depression without adverse endocrine and circulatory changes, nalbuphine still retains its analgesic property [30].In our study,respiratory depression was not associated with age.Patients in both age groups(18-64 y and $>65$ y) had more respiratory depression in the PF group than in the PN group. This suggests that there may be no association of age and reduced incidence of respiratory depression with nalbuphine use, which will need further research.

When respiratory depression occurs during ERCP,it may cause hypoxia, which can mostly be treated with the jaw-thrust manoeuvre [29, 31]. This phenomenon was particularly evident in the PN group. Compared to that in the PN group, the hypoxia in the PF group was more severe,as half of the patients were treated with more than one single method (jaw-thrust manoeuvre) to correct the hypoxia. This interrupted the operation, reduced the satisfaction ofthe endoscopists and anaesthesiologists, and increased the difficulties of anaesthesiologists' work. Therefore, nalbuphine had more advantages over fentanyl in reducing hypoxia in ERCP. However, general anaesthesia with endotracheal intubation became necessary when patients were at high risk for sedation-related adverse events. Compared to propofol-based monitored anaesthesia care, nalbuphine use did not impact the duration of the operation, the outcome of the procedure or patient recovery [32].

Our results are consistent with the findings of others that patients prefer to undergo the ERCP procedure under deep sedation and appropriate analgesia [21, 24]. Nalbuphine is a potentanalgesic agent that is similar to morphine $[27,28]$. Studies have shown that nalbuphineis widely used in pain management during the perioperative period $[29,33,34,35]$. Our results showed that nalbuphine was as effective as fentanyl in reducing pain-induced patient movement, and there was no difference in dosage. Patients in both groups had stable haemodynamics during the operation, which suggested that nalbuphine was effective in relieving painful stimuli and reducing adverse events upon completion of the procedure.

We also compared adverse events, such as nausea, vomiting,pruritus, and pain, after surgery between the two groups.Both groups had a slightly higher incidence of adverse reactions(e.g., nausea and fever)compared to groups receiving analgesic drugs in other studies [36, 37], likely due to procedure (ERCP)-related responses [1].The incidence of vomiting was similar to that in other studies $[36,37]$.One patient in each group had brief polypnea and dyspnoea after the operation, and both cases improved by nasal oxygen supplementation. Although the reason is still unclear, it may be related to patient anxiety or delayed response of respiratory depression to analgesic drugs [37].Some patients had abdominal pain one day after surgery, but none had severe pain. Few patients received medical treatment for adverse events, and all patients were discharged from the hospital approximately 7 days after the operation. There was no difference in the length of hospitalization between the two groups.Moreover, other researchers have shown that nalbuphine can be used to treat opioid-induced urinary retention and pruritus $[38,39]$, which makes it an option to be used together with opioids for procedures such as ERCP.

Our study also has some limitations. This is a singlecentre trial with a relatively small patient number. A larger-scale study with more patients in multiple centres is needed in the future.

\section{Conclusions}

In conclusion, we demonstrated that sedation with propofol-nalbuphine had advantages over propofolfentanyl for the ERCP procedure because the former produced less respiratory depression and surgical interruption. Furthermore, nalbuphine can produce adequate analgesia and help to maintain stable haemodynamics in patients undergoing ERCP.Therefore, acombination of propofol and nalbuphineis more efficient and safer for patients during procedural sedation in ERCP.

\section{Abbreviations \\ ERCP: Endoscopic retrograde cholangiopancreatography; PN: Propofol- nalbuphine; PF: Propofol-fentanyl; MRCP: Magnetic resonance cholangiopan- creatography; EUS: Endoscopic ultrasound; PLA: Chinese People's Liberation Army; BMI: Body mass index; ASA: American Society of Anesthesiologists; BIS: Bispectral index; HR: Heart rate; NBP: Noninvasive mean blood pressure; RR: Respiratory rate; SpO2: Oxygen saturation; PSSI: Patient sedation satisfac- tion assessment tool; VAS: Visual analogue score.}

\section{Acknowledgements}

An independent data analysis was commissioned by the Medical Management Institute for Public Health (PLA General Hospital, China) who formatted the data for analysis and undertook a preliminary interrogation of the data. Data collection would not have beenpossible without the assistance of Weili Zhang and Yan Wang. The authors acknowledge the contribution of colleagues.

\section{Authors' contributions}

WDM and LHX conceived and designed the experiments. PQW and YG performed the experiments. HW analysed the data. YC and JBC contributed to 
the follow-up visits/registration. PQW, LHX and YC wrote the manuscript. All authors read and approved the final manuscript.

\section{Funding}

Not funded

\section{Availability of data and materials}

All data generated or analysed during this study are included in this published article.

\section{Declarations}

\section{Ethics approval and consent to participate}

This study was approved by the ethics committee of Chinese PLA General Hospital (S2017-075-02) and was registered in the Chinese Clinical Trial Registry (ChiCTR1800016018). All patients provided written informed consent to participate, and this study was completed in accordance with the Strengthening the Reporting of Observational Studies in Epidemiology (STROBE) guidelines.

\section{Consent for publication \\ Not applicable}

\section{Competing interests}

The authors declare that they have no competing interests.

\section{Author details}

${ }^{1}$ Department of Anaesthesiology, The First Medical Center, Chinese PLA General Hospital, Beijing 100853, China. ${ }^{2}$ Department of Anaesthesiology, The Third Medical Center, Chinese PLA General Hospital, Beijing 100853, China.

Received: 21 July 2021 Accepted: 24 January 2022

Published online: 16 February 2022

\section{References}

1. Baiu I, Visser B. Endoscopic Retrograde Cholangiopancreatography. JAMA. 2018;320(19):2050.

2. D'Souza SL, Holub JL, Pavic BT, Rodriguez SA. Multicenter evaluation of the utilization of endoscopic ultrasound. Dig Endosc. 2016;28(7):738-43.

3. Dillman JR, Patel RM, Lin TK, Towbin AJ, Trout AT. Diagnostic performance of magnetic resonance cholangiopancreatography (MRCP) versus endoscopic retrograde cholangiopancreatography (ERCP) in the pediatric population: a clinical effectiveness study. Abdom Radiol (NY). 2019:44(7):2377-83

4. Huang RJ, Thosani NC, Barakat MT, Choudhary A, Mithal A, Singh G, et al. Evolution in the utilization of biliary interventions in the United States: results of a nationwide longitudinal study from 1998 to 2013. Gastrointest Endosc. 2017:86(2):319-26e5.

5. Mazen Jamal M, Yoon EJ, Saadi A, Sy TY, Hashemzadeh M. Trends in the utilization of endoscopic retrograde cholangiopancreatography (ERCP) in the United States. Am J Gastroenterol. 2007;102(5):966-75.

6. Cahen DL, Gouma DJ, Nio Y, Rauws EA, Boermeester MA, Busch OR, et al. Endoscopic versus surgical drainage of the pancreatic duct in chronic pancreatitis. N Engl J Med. 2007;356(7):676-84.

7. Standards of Practice Committee of the American Society for Gastrointestinal E, Lichtenstein DR, Jagannath S, Baron TH, Anderson MA, Banerjee $\mathrm{S}$, et al. Sedation and anesthesia in Gl endoscopy. Gastrointest Endosc. 2008;68(5):815-26.

8. Menon K, Barkun AN, Romagnuolo J, Friedman G, Mehta SN, Reinhold C, et al. Patient satisfaction after MRCP and ERCP. Am J Gastroenterol. 2001;96(9):2646-50.

9. Cote GA. Patient-controlled propofol for sedation in endoscopic retrograde cholangiopancreatography: an alternative to anesthesia-administered sedation? Gastroenterology. 2014;146(7):1818-9.

10. Haytural C, Aydinli B, Demir B, Bozkurt E, Parlak E, Disibeyaz S, et al. Comparison of Propofol, Propofol-Remifentanil, and Propofol-Fentanyl Administrations with Each Other Used for the Sedation of Patients to Undergo ERCP. Biomed Res Int. 2015;2015:465465.
11. Goyal R, Hasnain S, Mittal S, Shreevastava S. A randomized, controlled trial to compare the efficacy and safety profile of a dexmedetomidineketamine combination with a propofol-fentanyl combination for ERCP. Gastrointest Endosc. 2016;83(5):928-33.

12. Akhondzadeh R, Ghomeishi A, Nesioonpour S, Nourizade S. A comparison between the effects of propofol-fentanyl with propofol-ketamine for sedation in patients undergoing endoscopic retrograde cholangiopancreatography outside the operating room. Biomed J. 2016;39(2):145-9.

13. Bell GD, Bown S, Morden A, Coady T, Logan RF. Prevention of hypoxaemia during upper-gastrointestinal endoscopy by means of oxygen via nasal cannulae. Lancet. 1987;1 (8540):1022-4.

14. Jurell KR, O'Connor KW, Slack J, Fraiz J, Shaar CJ, Kent L, et al. Effect of supplemental oxygen on cardiopulmonary changes during gastrointestinal endoscopy. Gastrointest Endosc. 1994;40(6):665-70.

15. Committee ASoP, Early DS, Lightdale JR, Vargo JJ, Acosta RD, Chandrasekhara V, et al. Guidelines for sedation and anesthesia in Gl endoscopy. Gastrointest Endosc. 2018;87(2):327-37 (2nd).

16. Zsigmond EK, Durrani Z, Barabas E, Wang XY, Tran L. Endocrine and hemodynamic effects of antagonism of fentanyl-induced respiratory depression by nalbuphine. Anesth Analg. 1987;66(5):421-6.

17. Lefevre B, Freysz M, Lepine J, Royer JM, Perrin D, Malka G. Comparison of nalbuphine and fentanyl as intravenous analgesics for medically compromised patients undergoing oral surgery. Anesth Prog. 1992;39(1-2):13-8.

18. Preston KL, Bigelow GE, Liebson IA. Antagonist effects of nalbuphine in opioid-dependent human volunteers. J Pharmacol Exp Ther. 1989;248(3):929-37.

19. Pick CG, Paul D, Pasternak GW. Nalbuphine, a mixed kappa 1 and kappa 3 analgesic in mice. J Pharmacol Exp Ther. 1992;262(3):1044-50.

20. Song JC, Lu ZJ, Jiao YF, Yang B, Gao H, Zhang J, et al. Etomidate Anesthesia during ERCP Caused More Stable Haemodynamic Responses Compared with Propofol: A Randomized Clinical Trial. Int J Med Sci. 2015;12(7):559-65.

21. Garewal D, Powell S, Milan SJ, Nordmeyer J, Waikar P. Sedative techniques for endoscopic retrograde cholangiopancreatography. Cochrane Database Syst Rev. 2012(6):CD007274.

22. Nilsson A, Grossmann B, Kullman E, Uustal E, Sjoberg F, Nilsson L. Sedation during endoscopic retrograde cholangiopancreatography: a randomized controlled study of patient-controlled propofol sedation and that given by a nurse anesthetist. Scand J Gastroenterol. 2015;50(10):1285-92.

23. Lee TH, Lee CK, Park SH, Lee SH, Chung IK, Choi HJ, et al. Balanced propofol sedation versus propofol monosedation in therapeutic pancreaticobiliary endoscopic procedures. Dig Dis Sci. 2012;57(8):2113-21.

24. Berzin TM, Sanaka S, Barnett SR, Sundar E, Sepe PS, Jakubowski M, et al. A prospective assessment of sedation-related adverse events and patient and endoscopist satisfaction in ERCP with anesthesiologist-administered sedation. Gastrointest Endosc. 2011;73(4):710-7.

25 Errick JK, Heel RC. Nalbuphine A preliminary review of its pharmacological properties and therapeutic efficacy. Drugs. 1983;26(3):191-211.

26. Lewis JR. Evaluation of new analgesics. Butorphanol and nalbuphine JAMA. 1980;243(14):1465-7.

27. Larsen D, Maani CV. Nalbuphine. StatPearls. Treasure Island (FL)2020.

28. Davis MP, Fernandez C, Regel S, McPherson ML. Does nalbuphine have a niche in managing pain? J Opioid Manag. 2018;14(2):143-51.

29. Deng C, Wang X, Zhu Q, Kang Y, Yang J, Wang H. Comparison of nalbuphine and sufentanil for colonoscopy: A randomized controlled trial. PLoS One. 2017;12(12):e0188901.

30. Latasch L, Probst S, Dudziak R. Reversal by nalbuphine of respiratory depression caused by fentanyl. Anesth Analg. 1984;63(9):814-6.

31. Qin Y, Li LZ, Zhang XQ, Wei Y, Wang YL, Wei HF, et al. Supraglottic jet oxygenation and ventilation enhances oxygenation during upper gastrointestinal endoscopy in patients sedated with propofol: a randomized multicentre clinical trial. Br J Anaesth. 2017;119(1):158-66.

32. Smith ZL, Mullady DK, Lang GD, Das KK, Hovis RM, Patel RS, et al. A randomized controlled trial evaluating general endotracheal anesthesia versus monitored anesthesia care and the incidence of sedation-related adverse events during ERCP in high-risk patients. Gastrointest Endosc. 2019;89(4):855-62.

33. Eladi IA, Mourad KH, Youssef AN, Abdelrazek AA, Ramadan MA. Efficacy and Safety of Intravenous Ketorolac versus Nalbuphine in Relieving Postoperative Pain after Tonsillectomy in Children. Open Access Maced J Med Sci. 2019;7(7):1082-6. 
34. Peyrol M, Barraud J, Cautela J, Maille B, Laine M, Bonello L, et al. Controlled sedation with midazolam and analgesia with nalbuphine to alleviate pain in patients undergoing subcutaneous implantable cardioverter defibrillator implantation. J Interv Card Electrophysiol. 2017;49(2):191-6.

35. Tsai HL, Chang TK, Su WC, Yeh YS, Huang CW, Ma CJ, et al. Comparing efficacy and safety between Naldebain((R)) and intravenous patient-controlled analgesia with fentanyl for pain management post-laparotomy: study protocol for a randomized controlled, non-inferior trial. Trials. 2019:20(1):173.

36. Chretien B, Dolladille C, Hamel-Senecal L, Sassier M, Faillie JL, MiremontSalame G, et al. Comparative study of hypoglycaemia induced by opioids Is it a class effect? Expert Opin Drug Saf. 2019;18(10):987-92.

37. Dinges HC, Otto S, Stay DK, Baumlein S, Waldmann S, Kranke P, et al. Side Effect Rates of Opioids in Equianalgesic Doses via Intravenous PatientControlled Analgesia: A Systematic Review and Network Meta-analysis. Anesth Analg. 2019;129(4):1153-62.

38. Tubog TD, Harenberg JL, Buszta K, Hestand JD. Prophylactic Nalbuphine to Prevent Neuraxial Opioid-Induced Pruritus: A Systematic Review and Meta-Analysis of Randomized Controlled Trials. J Perianesth Nurs. 2019:34(3):491-501e8.

39. Jannuzzi RG. Nalbuphine for Treatment of Opioid-induced Pruritus: A Systematic Review of Literature. Clin J Pain. 2016;32(1):87-93.

\section{Publisher's Note}

Springer Nature remains neutral with regard to jurisdictional claims in published maps and institutional affiliations.

- fast, convenient online submission

- thorough peer review by experienced researchers in your field

- rapid publication on acceptance

- support for research data, including large and complex data types

- gold Open Access which fosters wider collaboration and increased citations

- maximum visibility for your research: over $100 \mathrm{M}$ website views per year

At BMC, research is always in progress.

Learn more biomedcentral.com/submissions 